\title{
Motherhood in Management: A Paradigm Shift
}

\author{
Dr. Sujit Roy \\ Research and Statistical Analyst \& Guest Faculty, Kalyani University, WB
}

\begin{abstract}
The paper attempts to explore and narrate the emerging relationship between mothering and managing from the perspective of mothers who are professional managers working in private and public sector. The paper has tried to fathom in the intricate relationship between the processes of mothering and managing; to reveal power relationship structures of mothering and managing; and to correlate the issues of work outside home, domestic work-sharing, and family-size with the management process from the organisational point of view. The unit of study has been women in management position. The universe of study has comprised women managers and administrators who have been mothers from few private and public sector business organisations in Kolkata, India. The study has revealed the stressful and straining conditions of mothers in professional life due to dual roles of mothering as well as managing both in private and public life. Mothering being one of the most innate qualities of a woman seems to encompass the roles of managing so naturally. Mother-managers have been trying to make the most out of their professional life to strike a balance between private mother-life and public managerial-life.
\end{abstract}

Keywords: Motherhood, Management, Mother-managers, Identity of Mother-manager.

\section{Introduction}

Motherhood refers to the qualities or spirit of a mother. Women have both uterus and brain. That is why woman only give birth a child and become a mother, and mothering starts. Mothering is the social practice of nurturing and caring for dependent children. Mothering thus is a process which entails a female role for mothers in society. Motherhood thus begins with a biographical incident, whether conceiving, giving birth to, or adopting, a child and it refers to the state of being a mother. On the other hand, managing refers to becoming a boss - transition from individual contributor to managing others. Management is thus a process of getting things done by an organisation to achieve organisational goals effectively and efficiently. Both motherhood and management have been processes which have been continuous in the sense that the roles and responsibilities of motherhood and management do not end at a particular point of time. A mother-manager is a mother who is also a manager.

Williams (2000) has outlined the relationship between motherhood and management, which has been constrained by different factors. The factor of organisational entitlement to demand an ideal manager free from any baggage of family work is a very limiting constraint on the relationship between mothering and managing. The second constraint is the right of husbands' vis-à-vis duty of wives who are also mothers. The third constraint involves the definition of the duties of a mother, as someone whose life should be framed around care giving. The contradictions of motherhood have been pointed out by Hays (1996) in that a mother must recognize and conscientiously respond to all the child's needs and desires, and to every stage of the child's emotional and intellectual development as defined by experts and demanded by the family and idealised by the media. This has been an emotionally taxing job for a mother-manager.

Again, mothering and motherhood can be viewed as 'soft power' in that both are related with nurturing, protecting and training children. This 'softness' should not be taken literally. It is more with persuasive and subtle power of mothers to take control of their children and family than the disciplinarian approach of hard taskmasters as demanded by the authority in managing organisations with 'hard power'. This soft power primarily refers to personal resources used by women using different power strategies like beauty, nurturing ability, friendship, affection or strength of personality as envisaged by Sen (2007). This soft power has been contrasted by conceptualizing concrete resources like money, skill, knowledge, or physical strength at men's disposal as hard power, used by them in a crude manner. The three issues of work outside home, domestic work-sharing, and family-size have been managed by mother-managers with their soft-power. Thus, women have been expected to fit in to the male model of work (Kelly, 1997).

The study tries to explore, examine and analyse the emerging issues of motherhood in management from the perspective of mothers who are professional managers working in private and public sector. The paper tries to ascertain relationship between the processes of motherhood and management from the perspective of power matrix. The study would also examine how far mother-managers consider management roles as mother roles. The paper also tries to explore the identity of mother-managers as perceived by themselves both in private and public life. 


\section{Literature Review}

Snow and Anderson (1987) opined that, when an individual views a particular identity as the central point of inflexion, he or she is likely to engage in behavior that reinforces that identity to self and others. Mothers use motherhood as the central identity in almost all social life. A woman may become a mother by giving birth or adopting a child, but she truly takes on a mother identity by playing a socially defined role, which is publicly visible. Then the process of mothering starts. These experiences influence personal identities of mothers. Working mothers, particularly mother-managers, portrayed by the media and experts as neglectful and a threat to their children's emotional development, are desperate to show that they can be supermoms, managing to work as well as raise happy, healthy children and maintaining a blissful marriage (Eyer, 1996).

The identity of a mother is very distinctive. It is an all-inclusive identity pervading not only the personal identity of a woman but also the cultural identity as a mother in a society. That is why, being someone's mother is not enough. The success of a mother is measured by her child's success and achievement in life. Tardy (2000) opined that a child's goodness and success is seen as the results of a mother's material instincts, her worth as a human being. Goffman (1959) suggested that "mothers also manage their and their children's appearances". Appearances can be anything like clothing, grooming, habits, surroundings, props, and verbal or nonverbal actions. Managing the motherly appearance might dictate carrying a diaper bag. Manning (1992) has opined that mothers are very aware of managing their impressions as good mothers and driven by a fear of unpleasant scenes in which the presented self may differ from the projected self. Mullaney (1999) asserted that the ability of actors to perform in a way that convinces others of their identity is a crucial factor in identity management. Goffman (1959) opines that impression management is nothing but selective selfpresentation -"accentuating certain facts and concealing others". The main goal of self-presentation is to help maintain a single definition of the situation and ensure smooth interaction. So, impression management is verily related to self-concept (Gecas, 1982), self-esteem (Brown, Collins, and Schmidt 1988), efficacy, mood, and selfbeliefs (McKillop, Berzonsky, and Schlenker 1992).

Then, there has been the case of 'maternal wall'. The issue of 'maternal wall', the term coined by Williams (2003), has been affecting the relationship between mothering and managing in that the mothermanagers have been facing peculiar kind of male-centric obstacles in the so-called modern management culture. Human resource management issues of hiring, promotions, pay, and even terminations have become very much pertinent with respect to gender justice to be meted out to mother-managers. Because, mother-managers have not been similarly situated to male managers or women managers without children. But, the maternal wall is not insurmountable. Porter (2006) has of the opinion that mothering and motherhood can be combined with a successful career. Again, the issue of 'Work-Life Balance (WLB)' has assumed an important place in life of mother-managers. Flexi-time, job-sharing, and other flexibility initiatives from the part of the organisations have become important resource inputs for the mother-managers in managing both private and public life in a balanced way. Gallegos (2007) has found that the majority of women have indicated that workplace flexibility was essential in juggling the demands of both family and work.

The study of Peters et. al. (2010) explored the ways in which organisational cultures alter when the 'glass ceiling' is shattered and a 'critical mass' of women is in senior executive roles. The study revealed that for many executive women the masculinity of managerial cultures is still deeply entrenched despite strong and explicit commitment to equal employment opportunity legislation in place in Australia for many decades. Many women interviewees commented bitterly on contradictory organisational responses to domestic responsibilities, especially child-care. In the study the myths of merit, motherhood and masculinist management are being contested and disrupted.As per the Grant Report (2014), it has been revealed of the scenario of having fewer children alleviating childcare pressures and freeing up mothers to pursue their careers. Meanwhile, urbanisation presents new opportunities and raises aspirations, leading to women choosing to have children later in life, further lowering fertility rates among mother-managers. However, the movement to cities also breaks down traditional models of extended families that provide in-built childcare infrastructure, enabling women to work full-time. Clearly, one of the keys to attracting and retaining women in companies is supporting them through motherhood, allowing them the time and flexibility to work and raise children at the same time.

\section{Research Objectives}

The specific objectives of the study have been as follows:

1. To ascertain the intricate relationship between the processes of motherhood and management;

2. To reveal dynamic relationship between motherhood and management from the perspective of power matrix;

3. To assess how far mother-managers consider management roles as mother roles;

4. To examine the issues of family life relating to motherhood from the organisational point of view;

5. To explore the issues of identity of mother-managers from the perspective of private mother-life and public managerial life. 


\section{Research Methodology}

Women in management position have been the unit of study. The universe of study has comprised of thirty-two women managers and administrators, who have been mothers, from few private and public sector business organisations in Kolkata, West Bengal, India in the month of June-July, 2015. The respondents have been randomly selected. All respondents have been assured that their identity would not be revealed in the study report. The semi-structured interview schedule with both open and close-ended questions has been used for the study. Interviews have been made to allow for significant details to emerge on important issues. Semi-structured interviews usually provide some points of reference between respondents and also allow space for the respondent to raise issues or questions that may not have been anticipated (Sarantakos, 1993). A qualitative method has been used in the research to collect rich descriptive data to get a comprehensive understanding of issues from the respondents' perspective, which is appropriate in this type of research (Babbie, 2002; Gilbert, 2001). This qualitative method of data collection is commonly used for research with women (Oakley, 2000). Thus, data with much variability and heterogeneity have been collected, and data analysis has been done appropriately.

\section{Findings \& Analysis}

\section{Business sectors and Age group distribution}

Mother-managers surveyed, numbering thirty-two in total, have been twenty in number $(62.50 \%)$ from private business sector and twelve in number (37.50\%) from public business sector. From the perspective of marital status, it has been found that twenty-four respondents have been leading normal conjugal life, two respondents have been widows, and the rest six respondents have been divorcees and singles.

Fig.1: Respondents from Business Sectors

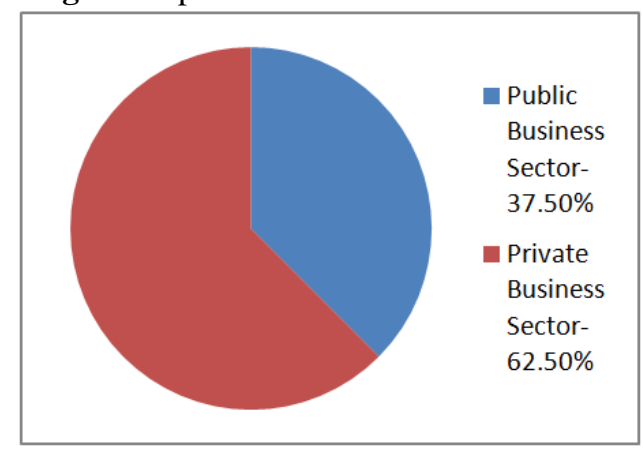

The age-distribution of respondents has been as follows: only $6.25 \%$ respondents have been in the age group of up to 30 yrs. - the young-aged group, $37.50 \%$ respondents in the age group of $31-45$ yrs. - the middleaged group, and the rest of the respondents $(56.25 \%)$ from the age group of 46-60 yrs.- the old-aged group.

Fig.2: Age group-wise distribution of Respondents

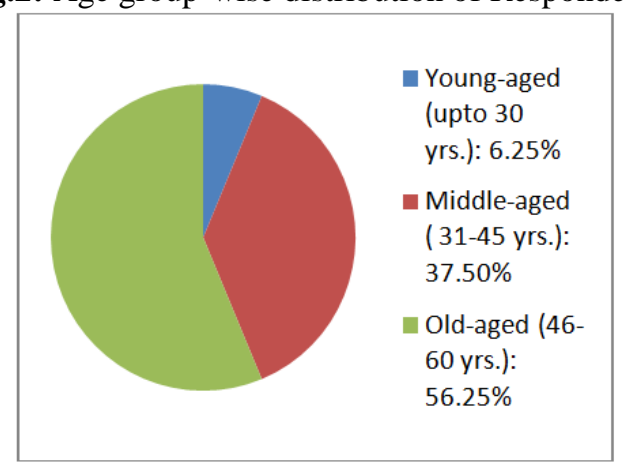

\section{Motherhood and Management process}

From the view point of the relationship of motherhood with the management roles in the organisations, $37.50 \%$ of the respondents have opined that there has been a strong positive relationship between motherhood and management roles. $25 \%$ respondents have a positive view for the same. But the rest of $37.50 \%$ respondents have opined in the negative and they have not considered the relationship between motherhood and management roles a worthy one in managing organisations. So the majority of the respondents have felt that the motherhood has a bearing on the management processes. 
Fig.3: Relationship between Motherhood and Management Roles

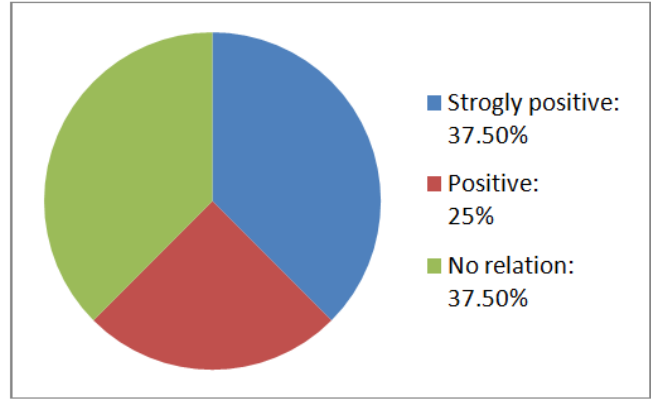

Again, while about one-third (33.33\%) respondents from the public sector have opined against any relationship between motherhood and managing roles, almost $40 \%$ respondents from the private sector have gone for the same. Overall the study has revealed that the majority of women managers have considered motherhood not as a debarring phenomenon but as an enhancer and a force multiplier in managing roles in organisations.

\section{Motherhood and Decision-making}

Decision-making has been the spirit and soul of organisational life. In each and every aspect of organisational and management processes, a manager has to take and make decisions to run an organisation efficiently and effectively. It has been found from the study that $62.50 \%$ respondents have thought that the decision-making processes in their management roles got a boost after they have become mother and considered motherhood as an asset with respect to managing roles in organisations. Only the rest of $37.50 \%$ respondents have opined in the negative and thought of no relationship of managerial decision-making ability with motherhood.

Fig.4: Mothering and Decision-making

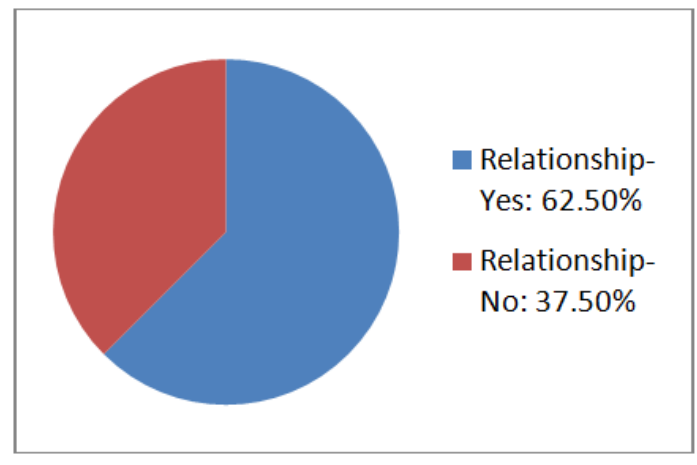

While the respondents from the public sector have been evenly distributed on the issue, the majority $(60 \%)$ of the respondents from the private sector have viewed the role of motherhood positively in managerial decision-making processes. It is probably due to the demanding, risk-fixing and uncertain nature of private sector which calls for more balanced decisions from managers. Herein comes the motherhood which sharpens women managers' decision-making ability considering the other way around.

To test whether there is any significant relationship between mother-managers from business-sectors of public and private businesses, and their decision-making processes, it has come out that (Table-1) there has been no significant relationship between business sectors and decision-making processes. It has implied that the nature of business organisations-whether it is public or private- have no bearing on the processes of decisionmaking of the mother-managers in their professional capacities.

Table 1: Test of Significance of Relationship between Business sector and Decision-making

\begin{tabular}{|lll|}
\hline \multicolumn{2}{|l|}{ Chi-Square Tests } \\
\hline Pearson Chi-Square \\
\hline Value df & Tabulated value \\
0.142 & 1 & 3.841 \\
\hline Decision & \\
No significance and Null hypothesis \\
accepted at 5\% level of significance
\end{tabular}




\section{Management and Male Roles}

Whether the management roles should be viewed as male roles is very pertinent from the perspective of motherhood. From the study it has come out that overall $62.50 \%$ mother-managers have been of the view that management roles are basically male roles. Rest of $37.50 \%$ respondents have opined that the management roles should not be viewed as male roles, but be considered as female roles having feminine ramifications. The sectorwise distribution of male-female management roles has shown an interesting revelation. While $66.67 \%$ mothermanagers from public business sector have opined in favour of management roles as male roles, $60 \%$ mothermanagers from private business sector have the same view-point. The results showed that the vast majority of mother-managers from both private and public sectors have been considering management processes from male perspective. It is probably due to male-centric patriarchal as well as organisational paradigm, entailing and encompassing the whole gamut of social life.

Fig.5: Management as Male and Female Roles

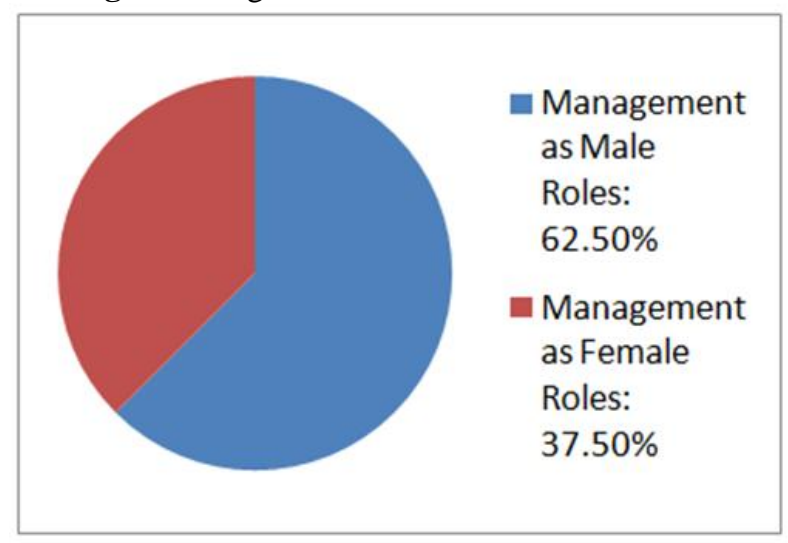

Management is all about decision-making at different levels of organisation at different points of time from the perspective of power-matrix. Business organisations are no doubt dominated by male managers. That is why it is interesting to test whether there has been any significant relationship between mother-managers who consider management roles as female roles and their decision-making processes, it has come out that (Table-2) there has been no significant relationship between consideration of management as female roles and decisionmaking processes through which mother-managers have been going through. It implies that mother-managers considering management roles as female roles do not have any bearing on the decision-making processes in business organisations either of public or of private sectors.

Table 2: Test of Significance of Relationship between Decision-making and Female roles

\begin{tabular}{|llc|}
\hline \multicolumn{2}{|l|}{ Chi-Square Tests } \\
\hline Pearson Chi-Square \\
\hline Value & $\mathrm{df}$ & Tabulated value \\
3.556 & 1 & 3.841 \\
\hline $\begin{array}{l}\text { Decision } \\
\text { No significance and Null hypothesis } \\
\text { accepted at }\end{array} \%$ level of significance \\
\hline
\end{tabular}

Both public and private business organisations have organisational cultures of their own. Mothermanagers from both sectors have their own opinions about the consideration of organisational roles as mother roles. Now, it is interesting to test whether there is any significant relationship between mother-managers who consider management roles as mother-roles and their business sectoral association, it has come out that (Table3) there has been no significant relationship between managers from different business sectors and consideration of management roles as mother roles. It has implied that the nature of ownership of business sectors has no bearing on the consideration of organisational roles as mother roles by mother-managers.

Table3: Test of Significance of Relationship betweenBusiness sector and Mother roles

\begin{tabular}{|l|l|}
\hline Chi-Square Tests \\
\hline Pearson Chi-Square \\
\hline Value df $\quad$ Tabulated value \\
$0.14 \quad 1 \quad 3.841$ \\
\hline Decision & \\
No significance and Null hypothesis \\
accepted at 5\% level of significance \\
\hline
\end{tabular}




\section{Attitude of Bosses and Decision-making}

The respondents have been evenly divided on the issue of the attitude of their bosses on their motherhood as either supportive or indifferent. The half of the respondents have reported that they have got support from their bosses in mothering process in that their bosses have behaved in a sensible and humane manner. The rest of the respondents have experienced indifferent attitude from their bosses regarding their motherhood. This indifference has been strikingly much more experienced $(83.33 \%)$ by the respondents from the public sector, which has been much less (30\%) in the case of private sector. This may be due to archaic and bureaucratic culture of the public sector, which has made the bosses more rule-based and indifferent. In this context it is interesting to test whether there is any significant relationship between attitude of bosses and decision-making made by mother-managers, it has come out (Table-4) that there has been significant relationship between attitude of bosses and decision-making. It is quite natural that the attitude of bosses from both public and private sectors influences mother-managers to a large extent to take decisions on organisational affairs on their own.

Table 4: Test of Significance of Relationship between Attitude of Boss and Decision-making

\begin{tabular}{|lll|}
\hline \multicolumn{2}{|l|}{ Chi-Square Tests } \\
\hline Pearson Chi-Square \\
\hline $\begin{array}{c}\text { Value df } \\
8.54\end{array} \quad 1 \quad$ Tabulated value \\
\hline $\begin{array}{l}\text { Decision } \\
\text { Highly significant and Null hypothesis } \\
\text { rejected at 5\% level of significance }\end{array}$ \\
\hline
\end{tabular}

\section{Issues relating to Family and Management}

The issues of work outside home, domestic work-sharing and family-size relating to motherhood with the management processes have been studied from different perspectives.On the issue of domestic work-sharing, the halves of the respondents have gotten help from their spouses in managing domestic work. $37.50 \%$ mothermanagers including divorcees have responded that they have to manage domestic work single-handedly. Only $12.50 \%$ respondents have been managing domestic work completely through the domestic helps. The study has shown that work outside home and domestic work sharing have to be managed primarily by mother managers themselves. The domestic work culture has still been dominated by patriarchal mind-set with slow pace of changing attitude.

Fig.6: Domestic Work sharing

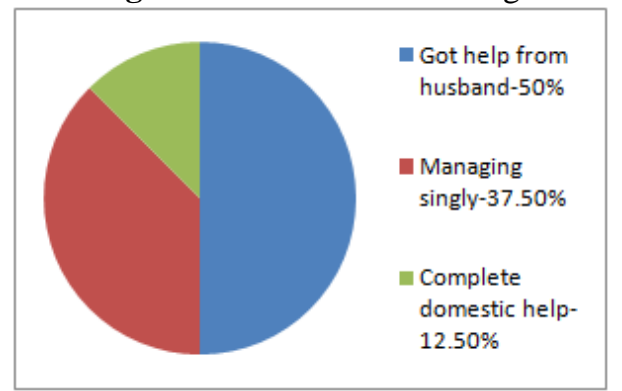

On the views of single-child family norm to be helpful to balance and manage family-career life, a vast majority of $62.50 \%$ respondents have expressed their opinions in favour of the same. While a small proportion of $12.50 \%$ respondents did not think of the single-child family norm to be helpful to balance and manage careerfamily life, a significant proportion of $25 \%$ respondents did not express any comment on the topic. The issue of single-child family norm seems to be very sensitive.

Fig.7: Single-child Family norm

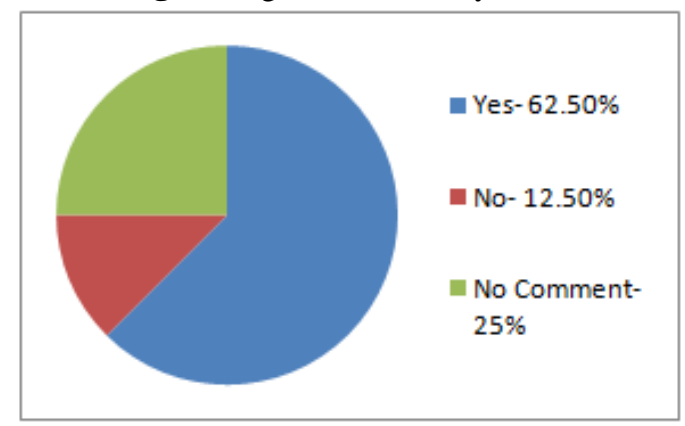


While the vast majority of $70 \%$ respondents from the private sector have gone for single-child family norm, only $50 \%$ respondents from the public sector have the same opinion. Again, no respondent from the private sector has gone against the single-child family norm, but $33.33 \%$ respondents from the public sector have opined against the single-child family norm. Lastly, while a significant proportion of $30 \%$ respondents from the private sector have no comment on the issue, only $16.67 \%$ mother-managers from the public sector did not provide any comment on the issue. It has shown that mother-managers from the private sector have an overwhelming preference to single-child family norm to cope with the demanding nature of job life compared to the mother-managers from the public sector.

Regarding the support network system in the areas of child-care facilities, day-care facilities, work flexibility, work-family life balance etc. provided by the organisations, all the respondents have informed that their organisations did not provide facilities like child-care or day-care to them. On the question of workflexibility provided by the organisation to the mother-managers as a part of the support network, the respondents have been evenly distributed in respect of ayes and nays.

But the interesting revelation is that all respondents from the public sector have informed that their organisations do not provide any type of work-flexibility like work from home etc. to the employees including mother-managers. The public sectors have no HRD policy regarding work-flexibility. On this issue, $80 \%$ of the respondents from the private sector have gotten flexible work schedules, to some extent, from their organisations to cope with maternal care in home. The response has been the same regarding the support system provided for the work-family life balance to the mother-managers from the private sector. In this case, only $16.67 \%$ respondents from the public sector have informed that they got some support from their organisations to make a balance in work-family life.

\section{Mother life and Managerial life Identity of Mother-managers}

On the question of identity as a mother and as a manager from the organisational perspective, the majority $(62.50 \%)$ of the respondents have opined that they consider themselves both as mother as well as manager. They identify themselves strongly as mother-managers and consider processes of mothering and managing as two sides of the same coin. On the other hand, $25 \%$ of the respondents have viewed two identities as separate and considered motherhood as a private identity with no relationship with public identity of managerial roles. Only miniscule proportions of $6.25 \%$ respondents have identified themselves both the roles as a form of motherhood and the same proportions of respondents $(6.25 \%)$ did not consider their identity from the perspective of motherhood-managerial paradigm.

While the majority $(66.67 \%)$ of the respondents from the public sector have viewed themselves both as mother and manager, the rest of $33.33 \%$ respondents have considered the two identities as separate. From the private sector, $60 \%$ of the respondents have viewed themselves both as mother and manager, $20 \%$ respondents considered the identities separately, $10 \%$ respondents- only motherhood and the rest of $10 \%$ did consider themselves neither from motherhood nor from managerial perspective.

Fig.8: Identity as Mother and Manager

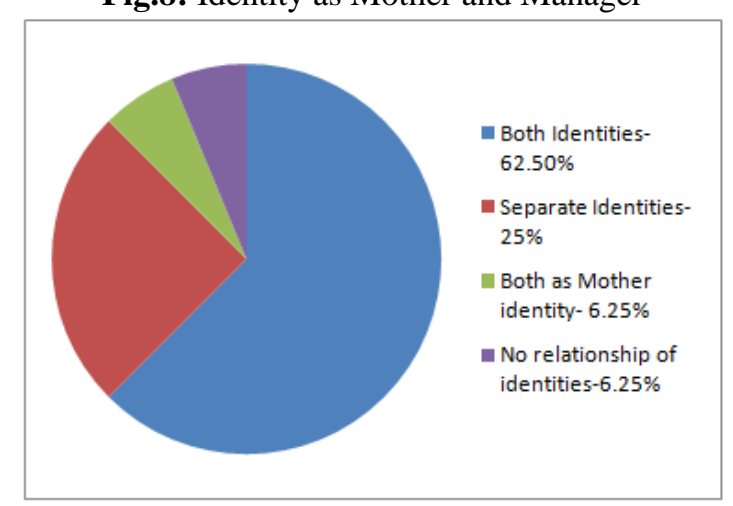

\section{Attitude of Bosses and Family-Career life}

The respondents have been evenly divided on the issue of the attitude of their bosses on their motherhood as either supportive or indifferent. The half of the respondents $(50 \%)$ have reported that they have got support from their bosses in mothering process in that their bosses have behaved in a sensible and humane manner. The rest of the respondents $(50 \%)$ have experienced indifferent attitude from their bosses regarding their motherhood. This indifference has been strikingly much more experienced $(83.33 \%)$ by the respondents from the public sector, which has been much less (30\%) in the case of private sector. This may be due to archaic 
and bureaucratic culture of the public sector, which has made the bosses more rule-based and indifferent to the sensitivity of mother-managers in their organisations.

Fig.9: Attitude of Bosses on Motherhood

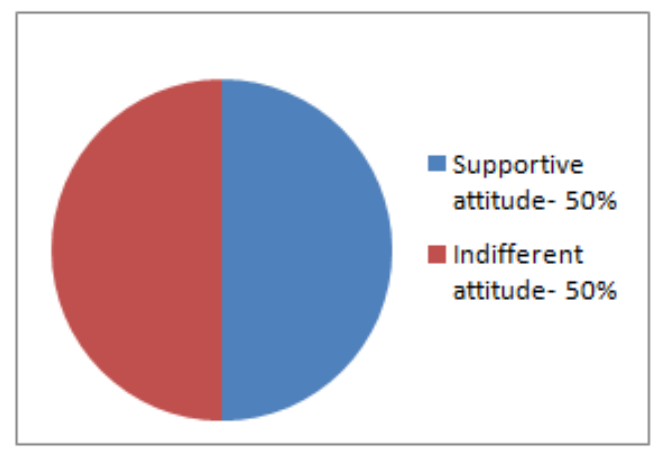

To test the relationship between attitude of bosses and choices in family-career life, it has come out (Table-5) that there has been significant relationship between attitude of bosses and choices in family-career life made by mother-managers. It has implied that supportive or indifferent bosses have made considerable influence on mother-managers to choose either family or career life.

Table 5: Test of Significance of Relationship between Attitude of Boss and Choice in Career-Family life

\begin{tabular}{|l|}
\hline Chi-Square Tests \\
\hline Pearson Chi-Square \\
\hline Value df $\quad$ Tabulated value \\
$8.541 \quad 1 \quad \quad \quad 3.841$ \\
\hline Decision \\
Highly significant and Null hypothesis \\
rejected at 5\% level of significance \\
\hline
\end{tabular}

\section{Mother-managers as Supermom}

The issue of 'supermom'-ism has acquired an interesting attention not only of the media but also of the academia. The majority $(62.50 \%)$ of the respondents- $(60 \%$ from the private sector and $66.67 \%$ from the public sector) - have considered themselves as 'supermom'- organizing, balancing and managing both the public and private spheres single-handedly. The rest of $37.50 \%$ respondents- (40\% from the private and $33.33 \%$ from the public sector) - have denied thinking of themselves like a supermom. They have been realistic not to be assessed on that parameter and try to balance between the demanding expectations from both home and office.

Fig.10: Respondents' feelings as Supermom

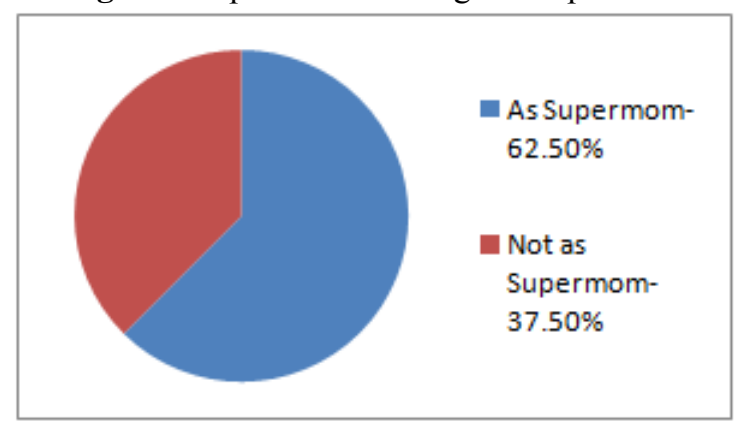

The choice between career in one hand and managing family-career life on the other has become a burning issue for mother-managers in modern life. The study has revealed that the majority of the respondents $(62.50 \%)$ have opined for the balance in family-career life. They have been trying their best to manage somehow both the family and career in life. The rest of respondents $(37.50 \%)$ have now been focusing more on career in life.

The age group-wise distribution of the choice between family and career in life has shown that the majority of respondents $(55.56 \%)$ from the old-aged group have now been concentrating more on career in life due to less burden in child-rearing as well as more time to spend for office life. But, the case has been diametrically opposite for the middle and young group of respondents. $83.33 \%$ of the respondents from the 
middle aged group have opined for the balance in family-career life and all respondents (100\%) from the young group have been for the same for balance in family-career life.

Fig.11: Choice between family and career life

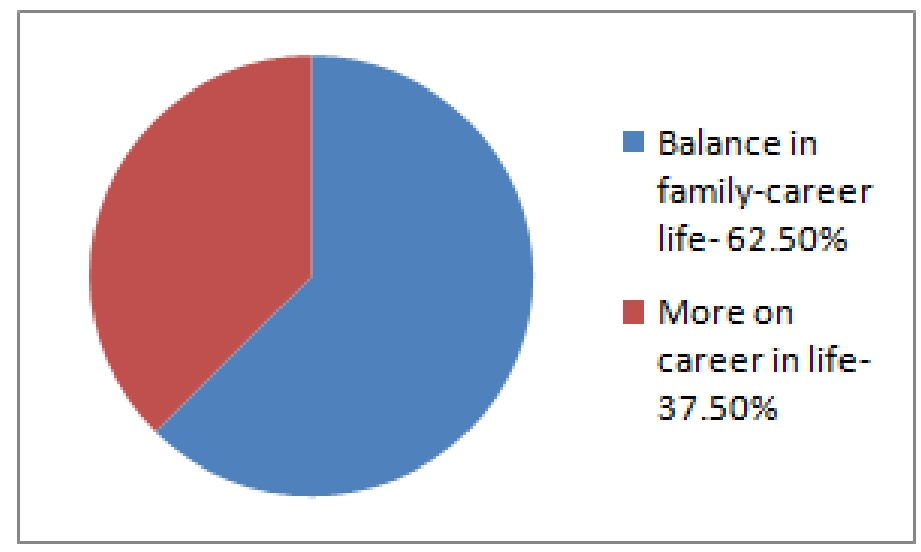

The issue has come out interestingly for the private-public dichotomy. While the two-third of the respondents $(67.67 \%)$ from the public sector has gone for career, $70 \%$ of the respondents from the private sector have opted for balance in family-career life. This opposite trend may be due to age factor as well as prospect of career-growth in two types of organisational set-up.

\section{Mother-guilt of mother-managers}

Mother-guilt has been very pertinent from the perspective of mind-set of mother-managers. It has been a sense of feeling which has been felt only by a mother, because of the patriarchal nature of our society. With the progress and development of our society, more and more women are now out of four-walled domestic family life. They are now becoming professionals in different walks of social life. But, the traditional as well as biological role of motherhood has an encircling effect on women who have now become both mother and manager. The dual roles have a telling effect on mother-managers. The study has revealed that only $31.25 \%$ of the respondents have feelings of mother-guilt and a miniscule proportion of $6.25 \%$ respondents have felt it sometimes. But, a vast majority of $62.50 \%$ respondents have no feelings of mother-guilt.

Fig.12: Respondents' feelings of mother-guilt

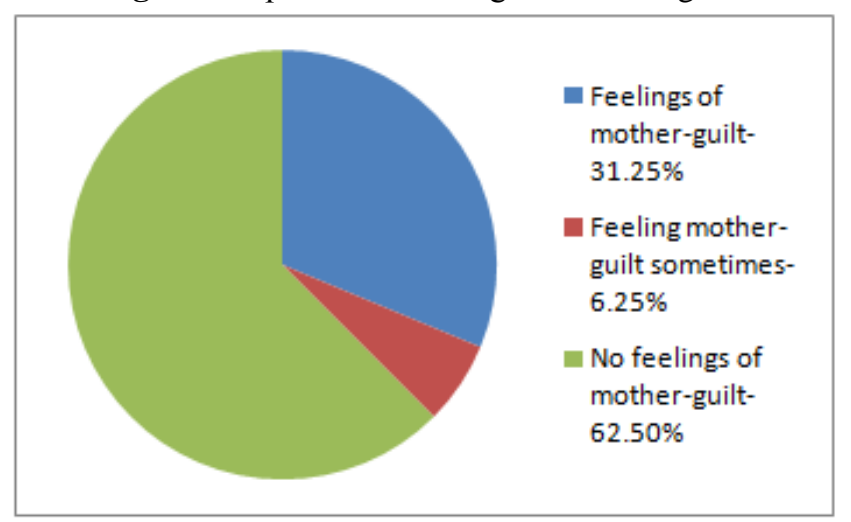

The age-wise distribution of mother-guilt has revealed that $50 \%$ respondents from the middle-aged group have feelings of mother-guilt, but $88.89 \%$ respondents from the old-aged group have no feelings of mother-guilt. From the public-private perspective, it has been revealed that a vast majority of $83.33 \%$ respondents from the public sector did not suffer from mother-guilt. But, it has been the case only for $50 \%$ respondents from the private sector. So, mother-managers from the private sector seem to feel guiltier compared to the public sector mother-managers. It may be due to demanding culture of private sector.

\section{Family-size norm}

Single-child family norm has now become an entrenched social culture, particularly for the urban professional group. On the question of whether single-child family is helpful to manage family-career life, important revelations have come out. The vast majority of respondents $(68.75 \%)$ have one child, and the balance of $31.25 \%$ respondents have two children. 
Fig.13: Respondents' family size

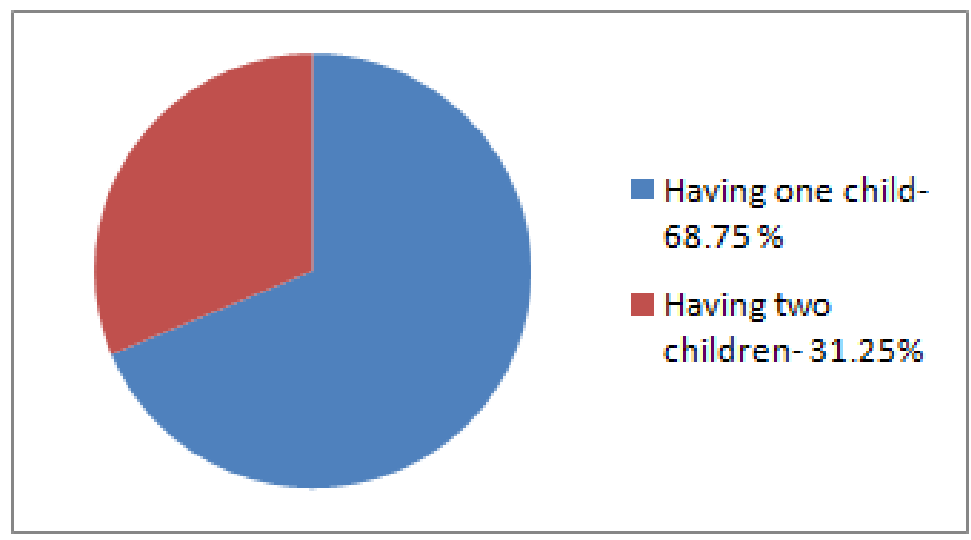

While respondents from the public sector have the same proportion of two types of families, $70 \%$ respondents from the private sector have one child. The age-wise distribution of family-size of respondents has shown that the proportion of two-child family has been more in old aged group (44.44\%) in compared with middle aged group (16.67\%) of mother-managers. The new millennium with its paraphernalia has set new norms, new values and new culture regarding family life and family-size from the perspective of organisational life.

\section{Conclusions}

The present study has revealed the stressful and straining conditions of mothers in professional life due to dual roles of mothering as well as managing both in private and public life. The study has revealed different inner layers of the intricate relationship between the processes of mothering and managing. Mothering being one of the most innate qualities of a woman seems to encompass the roles of managing so naturally. The narrative of mothering and managing may light up more areas of interest in structuring management roles from the perspective of motherhood. Mother-managers have been trying to make the most out of their professional life to strike a balance between private mother-life and public managerial life.

The study has its own limitations in that it has covered a very limited universe of respondents. The study has gone through few issues relating to motherhood and management. The scope of the present research study was very limited. So, it is no denying that the study has been a 'partial' one, leaving enough scope for further studies on the other aspects of mothering issues in managing roles in a larger perspective with different sections of larger society. The future work on the relationship between mothering and managing may be broaden by considering more mother-managers of this sector as well as other sections of social life. The future studies may open up new horizons of emerging relationship between motherhood and management roles from the perspective of different types of organisational life.

\section{References}

[1]. Babbie, E. 2002. The Basics of Social Research. California: Wadsworth/ Thomson Learning.

[2]. Brown, Jonathon D., Rebecca L. Collins, and Greg W. Schmidt. 1988. "Self-Esteem and Direct

[3]. Versus Indirect Forms of Self-Enhancement."Journal of Personality and Social Psychology 55:445-53.

[4]. Eyer, Diane. 1996. Motherguilt: How Our Culture Blames Mothers for What's Wrong with Society. New York: Random House.

[5]. Gecas, Viktor. 1982. "The Self-Concept.” Annual Review of Sociology 8:1-33.

[6]. Gilbert, N. (Ed.) 2001. Researching social life. 2nd Edition. London: Sage.

[7]. Goffman, Erving. 1952. "On Cooling the Mark Out: Some Aspects of Adaptation to Failure."

[8]. Psychiatry: Journal of Interpersonal Relations 15:451-63.

[9]. Gallegos, D. (2007). Managing Work and Motherhood: Implications for Perinatal Mental Health. Perth, Western Australia: State Perinatal Reference Group Department of Health, CSCR and WACRW.

[10]. Grant Thornton IBR. 2014. Women in business: the path to the boardroom. www.internationalbusinessreport.com accessed on 1009-2015.

[11]. Hays, Sharon. 1996. The Cultural Contradictions of Motherhood. New Haven, CT: Yale University Press.

[12]. Kelly, Rita Mae, and Georgia Duerst-Lahti. 1997. Gender Power, Leadership, and Governance. The Journal of Politics, Vol. 59, No. 2, pp. 606-609.

[13]. McKillop, Kevin J., Michael D. Berzonsky, and Barry R. Schlenker. 1992. "The Impact of Self-

[14]. Presentations on Self-Beliefs: Effects of Social Identity and Self-Presentational Context." Journal of Personality 60:789-808.

[15]. Manning, Phillip. 1992. Erving Goffman. Oxford: Polity Press.

[16]. Mullaney, Jamie. 1999. "Making it 'Count': Mental Weighing and Identity Attribution.” Symbolic Interaction 22(3):269-83.

[17]. Oakley, A. 2000. Experiments in method: gender and method in the social sciences. Oxford: Polity Press.

[18]. Peters, Margaret, Anne Ross-Smith, and Colleen Chesterman. 2010. "Merit, Motherhood, and Other Masculinist Management Myths: The Contradictory Experiences of Executive Women in Corporate Cultures". NASSM, Florida. 
[19]. Porter, Nicole Buonocore. 2006. "Re-defining Superwoman: An Essay on Overcoming The 'Maternal Wall' in The Legal Workplace". Duke Journal of Gender Law \& Policy Vol. 13:55.

[20]. Sarantakos S. 1993. Social Research. Melbourne: MacMillan Education Australia.

[21]. Sen, Bimla. 2007. Women Power- The Changing Scenario. Panchkula: Better Books.

[22]. Snow, David A. and Leon Anderson. 1987. "Identity Work Among the Homeless: The Verbal Construction and Avowal of Personal Identities.” American Journal of Sociology 92:1336-71.

[23]. Tardy, Rebecca. 2000. "But I Am a Good Mom': The Social Construction of Motherhood through Health-Care Conversations." Journal of Contemporary Ethnography 28:433-73.

[24]. Williams, Joan. 2000. Unbending Gender: Why Work and Family Conflict and What To

[25]. Do About It. Oxford: Oxford University Press.

[26]. ....... 2003. Beyond the Glass Ceiling: The Maternal Wall as a Barrier to Gender Equality. 26 T. Jefferson L. Rev. 1. 